\title{
Propagation Regularity of Air Shock Wave in Turning Roadway
}

\author{
Chunhui Song ${ }^{1}$, Xianglong Li ${ }^{1, ~ *, ~ Z i h a o ~ T a o ~}{ }^{1}, X_{\text {X Zhang }}^{2}$, Yingming Duan ${ }^{2}$ \\ ${ }^{1}$ Yunnan Key Laboratory of Sino-German Blue Mining and Utilization of Special Underground Space, Faculty of Land Resources Engineering, \\ Kunming University of Science and Technology, Kunming, China \\ ${ }^{2}$ Yuxi Mining Co., Ltd. Yuxi, China
}

Email address:

7988982@qq.com (Xianglong Li),253190165@qq.com (Chunhui Song)

${ }^{*}$ Corresponding author

\section{To cite this article:}

Chunhui Song, Xianglong Li, Zihao Tao, Xi Zhang, Yingming Duan. Propagation Regularity of Air Shock Wave in Turning Roadway. Engineering Science. Vol. 4, No. 3, 2019, pp. 43-53. doi: 10.11648/j.es.20190403.11

Received: October 15, 2019; Accepted: November 23, 2019; Published: December 5, 2019

\begin{abstract}
In order to study the propagation law of explosive shock wave in underground turning roadway, the peak overpressure value in the roadway with specific turning angle was compared and analyzed by combining field monitoring experiment with ANSYS numerical simulation. The results show that the blast wave propagates forward in a stable plane wave before turning. Before the explosion air shock wave propagates to the turn, it follows the propagation law in the straight through roadway. After turning, the diffraction and reflection through the wall of the roadway will form a turbulence zone of 10-20m, and then continue to propagate forward in a stable plane wave. The turning roadway has a certain attenuation effect on the propagation of the shock wave. By analyzing the peak overpressure value before and after turning, the attenuation coefficient values of roadways at various turning angles are determined, That is, the attenuation coefficient values corresponding to the turning angles of $30^{\circ}, 60^{\circ}, 90^{\circ}, 120^{\circ}$ and $150^{\circ}$ are $1.25,1.31,1.45,1.50,1.65$, respectively, and the attenuation coefficient values are fitted with the roadway turning angle formula to obtain the quantitative calculation formula, which can provide reference for the safety of underground personnel, equipment and the design and production of mines.
\end{abstract}

Keywords: Explosion Shock Wave, Turning Roadway, Numerical Simulation, Attenuation Coefficient

\section{Introduction}

As the purpose of the project changes, the complexity of the blasting site is also increasing, and blasting operations are more common in turning lanes. Therefore, it is especially important to study the propagation law of explosive shock waves in turning lanes to protect personal safety and equipment. For a long time, many research scholars at home and abroad have never stopped studying the air shock wave. Jia Zhiwei et al [1] found that the overpressure attenuating coefficient of the gas explosion shock wave in the general air zone has a relationship with the initial overpressure of the shock wave and the angle of the pipe bend under different corner angles of the pipeline, and established the relationship between them. Wu Yanjie et al [2] proposed the calculation method of shock wave overpressure correction, and corrected the numerical simulation results. The results show that the early empirical formulas and numerical simulation results are in the middle and lower values of the explosion shock wave overpressure, respectively. Underestimate the danger of explosion shock waves. Gong Jie, Wang Quan et al. [3] studied the propagation law of explosive shock waves in cylindrical explosive vessels, and found that the experimental test values and the traditional theoretical empirical formula calculated values have large errors and are corrected. Finally, based on the experimental test results and the principle of explosion similarity, the formula for calculating the shock wave overpressure in this environment is fitted. Miao Chaoyang, Yang Sen et al. [4] carried out experiments on plugging explosions of different dose tunnels, and used ANSYS/LSDYNA software to numerically calculate the explosion shock waves of the prototype tunnel and the model tunnel. Finally, the similar law of the explosion shock wave in the tunnel is obtained. Li Xiudi et al [5] simulated the effects of different charge locations and charge shapes on the 
propagation of explosion shock waves in tunnels. Lu Hongqin et al. [6] compared the effects of straight wall arches, equal-span rectangular, square and circular tunnel cross-section shapes on the shock wave propagation characteristics in tunnels. Britan A et al. [7] studied the propagation attenuation law of air shock waves in complex network structures, and proposed the safety protection design and concept of underground space to deal with shock wave damage effects. Weiss [8] discussed the measures for the protection of underground facilities and personnel in explosion accidents through the study of the anti-blasting impact of underground structures and facilities. KANG Y et al [9]. studied the law of crack growth under the action of blast wave through experiments, and simulated the evolution law of explosive stress wave and explosion-induced crack growth with ANSYS/ 1s-dyna. Results the relationship between the fracture zone and the natural fracture of rock containing natural fracture under the action of blast wave was obtained. LI Zhongxian et al [10]. used ls-dyna numerical simulation software to simulate the propagation law of blast wave in urban streets and its influence on surrounding buildings.

The results show that after multiple reflections between the street buildings, the blast wave intensifies and damages the surrounding buildings.

And in a certain height ratio range, the intensity of explosion load is proportional to the height of surrounding buildings.

(1) Many scholars have studied the principle of explosion similarity, the correction of the explosion shock wave overpressure calculation formula and the similar law of shock wave. Another part of the scholars studied the effects of different charge forms on the explosion shock wave, and made research on the blasting scale, explosive type, and charge structure, but most of them used the model to conduct research.

(2) Most scholars did not study the propagation law of shock waves for roadway types. Secondly, scholars [11-15] conducted research based on numerical simulation methods. They did not combine with reality and lacked real-world data for verification.

Therefore, this paper specifically studies the propagation law of the explosion shock wave in the turning lane, and uses the combination of numerical simulation and field test to analyze the law of the shock wave in detail, and finally draws the conclusion.

\section{Calculation Formula for Peak Overpressure in Turning Roadway}

The explosion process actually exists and follows the similarity law, and it also affects the three most important parameters of the blasting air shock wave properties: shock wave peak overpressure, positive pressure action time, shock wave impulse, It can also be obtained by dimensional analysis and experimental methods on the basis of similar theory.

Assume that the amount of TNT explosives in the roadway is the cross-sectional area of the roadway, and the corresponding TNT explosive equivalent in the air explosion. Refer to the Explosion and Impact Dynamics for an introduction to the explosion of the TNT charge in the roadway.

\subsection{Air Shock Wave Peak Overpressure Calculation in the Roadway with Open Ends}

In the case of opening at both ends of the roadway, the TNT explosive equivalent is equal to the peak overpressure of the air shock wave:

$$
\mathrm{Q}^{*}=\frac{4 \pi \mathrm{R}^{2}}{2 \mathrm{~S}} \mathrm{Q}=2 \pi \frac{\mathrm{R}^{2}}{\mathrm{~S}} \mathrm{Q}
$$

$\mathrm{R}$ is the propagation distance of the blasting air shock wave in the formula.

Therefore, in the roadway with both ends open, the TNT equivalent replacement is transformed by the formula (2):

$$
\begin{aligned}
& \Delta \mathrm{P}=\mathrm{a}_{1}\left(\frac{\sqrt[3]{\mathrm{Q}_{\mathrm{TNT}}}}{\mathrm{R}}\right)+\mathrm{a}_{2}\left(\frac{\sqrt[3]{\mathrm{Q}_{\mathrm{TNT}}}}{\mathrm{R}}\right)^{2}+\mathrm{a}_{3}\left(\frac{\sqrt[3]{\mathrm{Q}_{\mathrm{TNT}}}}{\mathrm{R}}\right)^{3} \\
& =a_{1}\left(\frac{\sqrt[3]{2 \pi \frac{\mathrm{R}^{2}}{\mathrm{~S}} \mathrm{Q}}}{\mathrm{R}}\right)+\mathrm{a}_{2}\left(\frac{\sqrt[3]{2 \pi \frac{\mathrm{R}^{2}}{\mathrm{~S}} \mathrm{Q}}}{\mathrm{R}}\right)^{2}+\mathrm{a}_{3}\left(\frac{\sqrt[3]{2 \pi \frac{\mathrm{R}^{2}}{\mathrm{~S}} \mathrm{Q}}}{\mathrm{R}}\right)^{3}
\end{aligned}
$$

The mathematical model of the blasting air shock wave overpressure peak in the roadway with both ends open is obtained by formula (2):

$$
\Delta \mathrm{P}=\mathrm{b}_{1}\left(\frac{\mathrm{Q}}{\mathrm{SR}}\right)^{\frac{1}{3}}+\mathrm{b}_{2}\left(\frac{\mathrm{Q}}{\mathrm{SR}}\right)^{\frac{2}{3}}+\mathrm{b}_{3}\left(\frac{\mathrm{Q}}{\mathrm{SR}}\right)
$$

\section{$b_{1}, b_{2}, b_{3}$ Both are pending coefficients.}

\subsection{Air Shock Wave Peak Overpressure Calculation in the Roadway with One End Open}

Assume that in the roadway with open ends: the energy released by the explosion is the cross-sectional area of the roadway; and the energy released by the explosion in the roadway with only one end is, according to the energy similarity criterion: the peak of the air shock wave is over-pressured when one end is open formula:

$$
\Delta \mathrm{P}=\mathrm{c}_{1}\left(\frac{\mathrm{Q}}{\mathrm{SR}}\right)^{\frac{1}{3}}+\mathrm{c}_{2}\left(\frac{\mathrm{Q}}{\mathrm{SR}}\right)^{\frac{2}{3}}+\mathrm{c}_{3}\left(\frac{\mathrm{Q}}{\mathrm{SR}}\right)
$$

$c_{1}, c_{2}, c_{3}$ Both are pending coefficients.

According to $\frac{\mathrm{E}_{0}^{\prime}}{2 \mathrm{~S}}=\frac{\mathrm{E}_{0}}{\mathrm{~S}}$, we can know, The undetermined coefficient $c_{1}, c_{2}, c_{3}$ in formula (4) and the coefficient $b_{1}, b_{2}, b_{3}$ in formula (3) exist: 


$$
c_{1}=1.26 b_{1}, c_{2}=1.59 b_{2}, c_{3}=2 b_{3}
$$

Therefore, the attenuation model of blasting air shock wave overpressure in the roadway with one end opening is:

$$
\Delta \mathrm{P}=1.26 \mathrm{~b}_{1}\left(\frac{\mathrm{Q}}{\mathrm{SR}}\right)^{\frac{1}{3}}+1.59 \mathrm{~b}_{2}\left(\frac{\mathrm{Q}}{\mathrm{SR}}\right)^{\frac{2}{3}}+2 \mathrm{~b}_{3}\left(\frac{\mathrm{Q}}{\mathrm{SR}}\right)
$$

$\mathrm{b}_{1}, \mathrm{~b}_{2}, \mathrm{~b}_{3}$ both are pending coefficients. It is consistent with the parameters of the peak overpressure calculation formula in the roadway with open ends.

The air shock wave will a certain degree of attenuation after passing through the turning roadway, but its peak overpressure may still cause damage to the personnel, equipment and blasting network in the shaft. Although the peak overpressure prediction formula derived in the previous article can calculate the overpressure value of the shock wave after passing through the turning roadway, But this value is only the overpressure value at which the shock wave forms a plane wave. Therefore, it is necessary to determine the peak overpressure value calculation formula that is transmitted to a certain point after the shock wave is turned to form a stable plane wave. The peak overpressure value at point $\mathrm{C}$ is obtained as an example in figure 1 below:

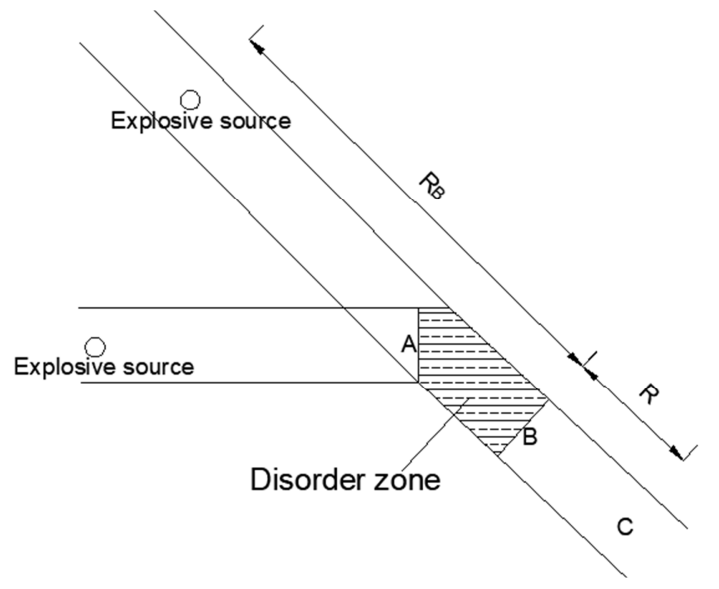

Figure 1. Schematic diagram of a point in the turning lane.

Assume that this turning roadway has only one end open, It is known that the amount of explosive in the explosion zone in the figure is $\mathrm{Q}$, The peak overpressure at the corner A can be

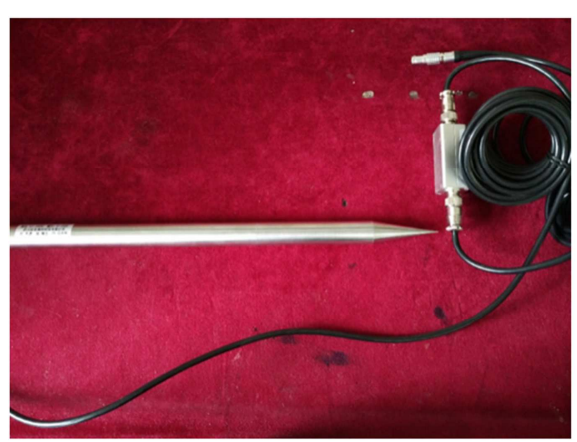

Shock wave sensor calculated by using the air shock wave peak overpressure prediction formula (5) in the tunnel with only one end opening. When the blasting shock wave reaches the corner, the peak overpressure will decay. Suppose the attenuation coefficient under this condition is $\lambda$, then, when the shock wave forms a stable plane wave through point $\mathrm{B}$, the peak overpressure has decayed to:

$$
\Delta \mathrm{P}_{\mathrm{B}}=\Delta \mathrm{P}_{\mathrm{A}} \times \lambda
$$

After solving the peak overpressure value of point $B$, the peak overpressure value is substituted into the previous peak overpressure prediction formula (5), and the peak overpressure corresponding to the conversion distance in the through-passway is calculated under the same explosive quantity condition, just like the above Figure 1 shown. After the distance is obtained, assuming that the point $\mathrm{C}$ is at a distance $m$ from the point $B$, the peak value of the shock wave at the point $\mathrm{C}$ after the turn can be calculated according to the prediction formula that is substituted with the blasting center.

\section{Blast Wave Propagation Field Studies in the Turn Lane}

In this chapter, the air shock wave generated by the blasting operation is monitored on-site in real time, and the measured data of the shock wave monitored on the site is analyzed and analyzed, and the peak overpressure and the peak overpressure attenuation coefficient of each turn angle roadway are obtained. Provide a certain field experimental data base for the next numerical simulation part.

\subsection{On-site Monitoring of Explosion Shock Waves}

\subsubsection{Introduction to On-site Monitoring Instruments}

The explosion not only produces air shock waves, but also comes with other forms of vibration and flying stones, and the air shock wave travels faster. Thus the entire test system requires a strong anti-interference ability, high reliability, faster response time and other characteristics, it should also have enough storage capacity to prevent accidental triggering of the external interference.

The equipment for on-site monitoring experiments used NUBOX-9012 blasting shock wave intelligent monitor and matching air shock wave pressure sensor, as shown in figure 2 .

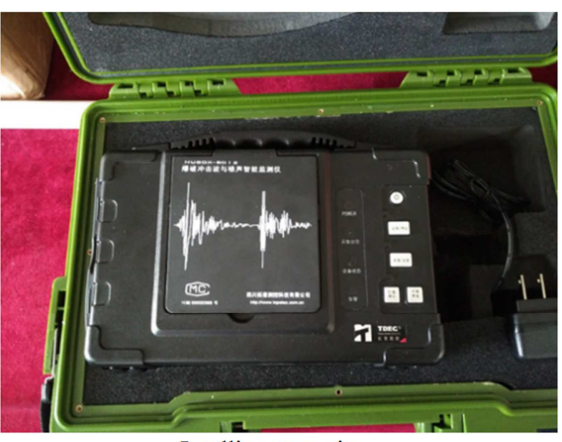

Intelligent monitor

Figure 2. Schematic diagram of shock wave monitoring equipment. 
Table 1. Main technical performance indicators of NUBOX-9012 intelligent monitor.

\begin{tabular}{ll}
\hline item & Plan indicator \\
\hline Measuring range & $0 \mathrm{Mpa}-2 \mathrm{Mpa}$ \\
Accuracy level & $\pm 3 \%$ o \\
Number of channels & Dual channel \\
Sampling Rate & Multi-program control, max 10 Msps \\
Display method & LCD \\
A/D resolution & $16 \mathrm{Bit}$ \\
Trigger mode & Trigger out of the window \\
storage space & $16 \mathrm{G}$ \\
Power supply & Built-in lithium battery \\
operating temperature & $0-50^{\circ} \mathrm{C}$ \\
\hline
\end{tabular}

\subsubsection{Working Principle of Monitoring System}

When the air shock wave generated by the explosive explosion propagates to the position of the sensor, the pressure sensor is triggered. The signal collected by the pressure sensor is converted into a corresponding voltage signal by a signal converter, and then the monitoring system automatically collects and stores it. Finally, the collected raw data is processed by TS-View analysis software. The entire monitoring system is shown in figure 3 .

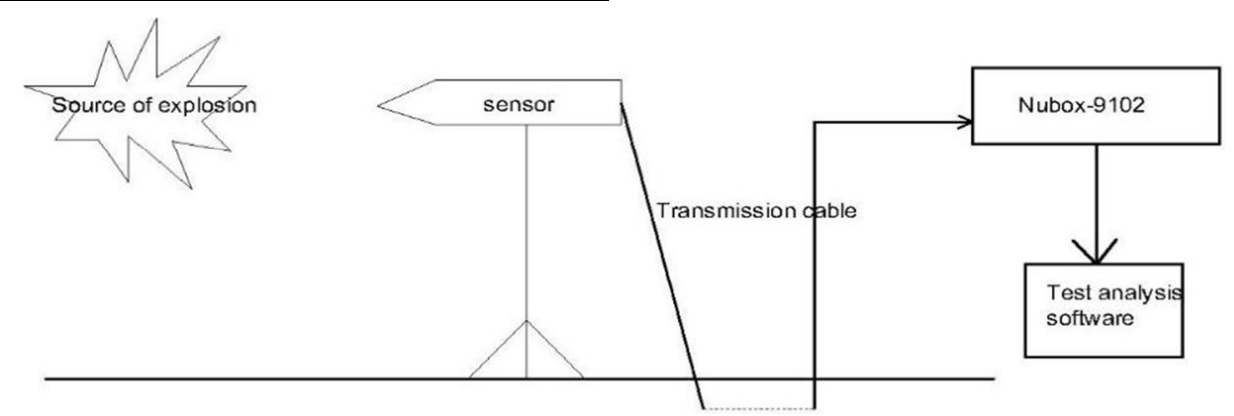

Figure 3. Schematic diagram of the working principle of the instrument.

\subsubsection{Monitoring Plan and On-site Monitoring}

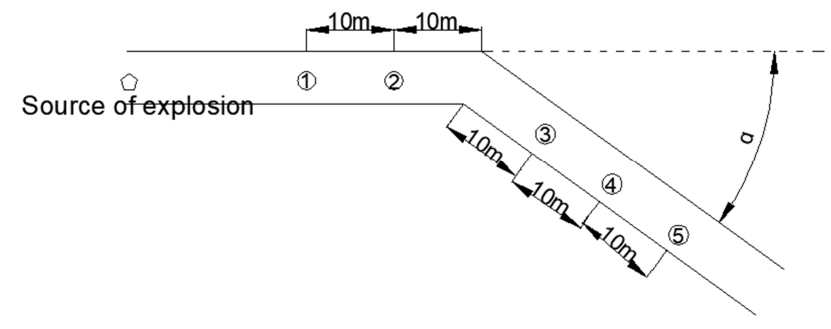

Figure 4. Turning roadway.

According to the specific monitoring of the roadway environment, the parameters of the instrument are debugged. To ensure that the instrument is not damaged by the explosion shock wave and does not exceed the maximum range of the sensor, the first instrument closest to the explosion zone is placed. Then, the remaining instruments are arranged in order according to the interval of $10 \mathrm{~m}$. For the case where there is a shape change in the turning lane, the center of the section with the change is taken as the arrangement point, and the instruments are also arranged at intervals of $10 \mathrm{~m}$, and the specific instrument layout is shown in figure 4.

Due to the large traffic volume and large number of personnel during the installation on site, taking into account the normal operation and traffic of the blasting personnel and the vehicle, the instrument is placed at a position $1 \mathrm{~m}$ away from the wall of the roadway during the actual installation, schematic and renderings. See figure 5.
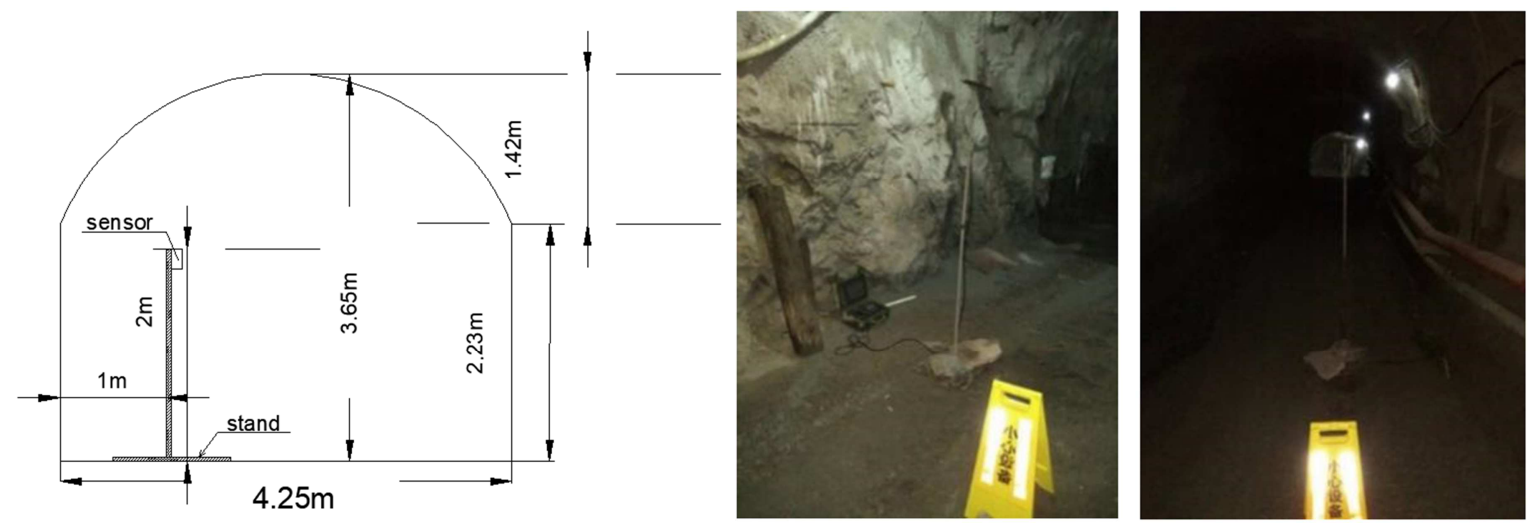

Figure 5. Measuring point design and scene rendering. 


\subsection{Analysis and Research of Data}

The monitoring data of the explosion air shock wave in the turning lane on the site is mainly concentrated in the roadway with turning angles of $30^{\circ}, 60^{\circ}$ and $90^{\circ}$. The raw data is shown in Table 2 . A typical waveform is shown in figure 6 .

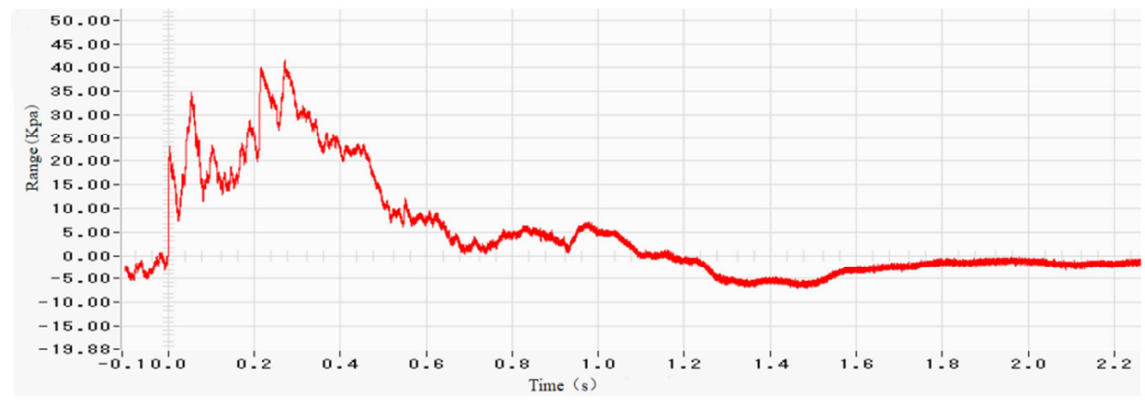

Measuring point 1

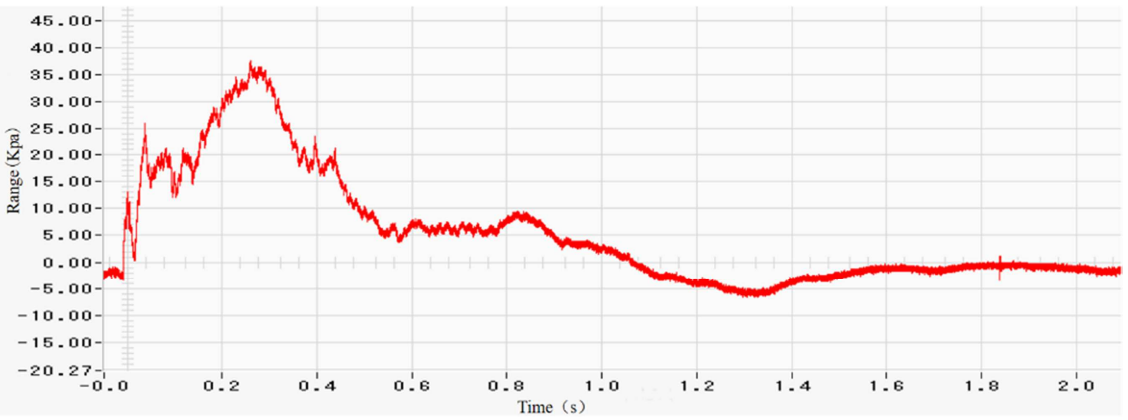

Measuring point 2

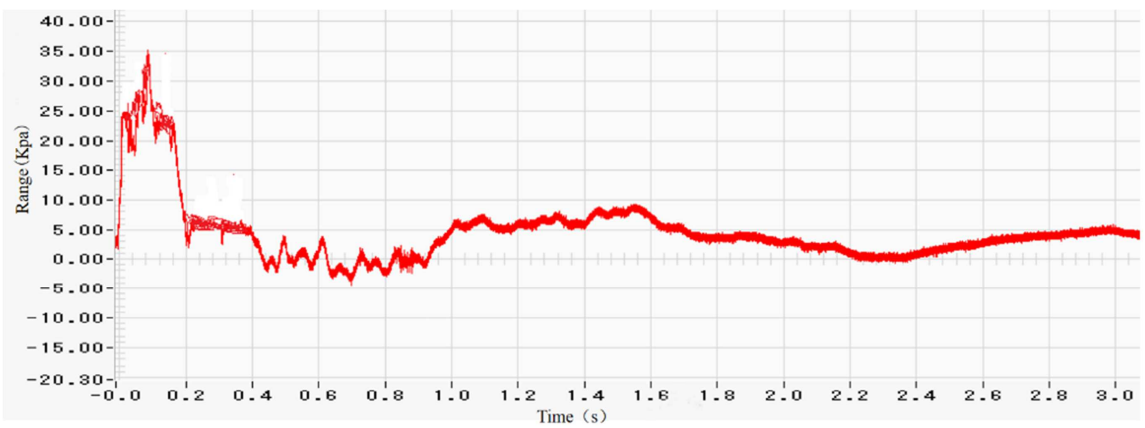

Measuring point 3

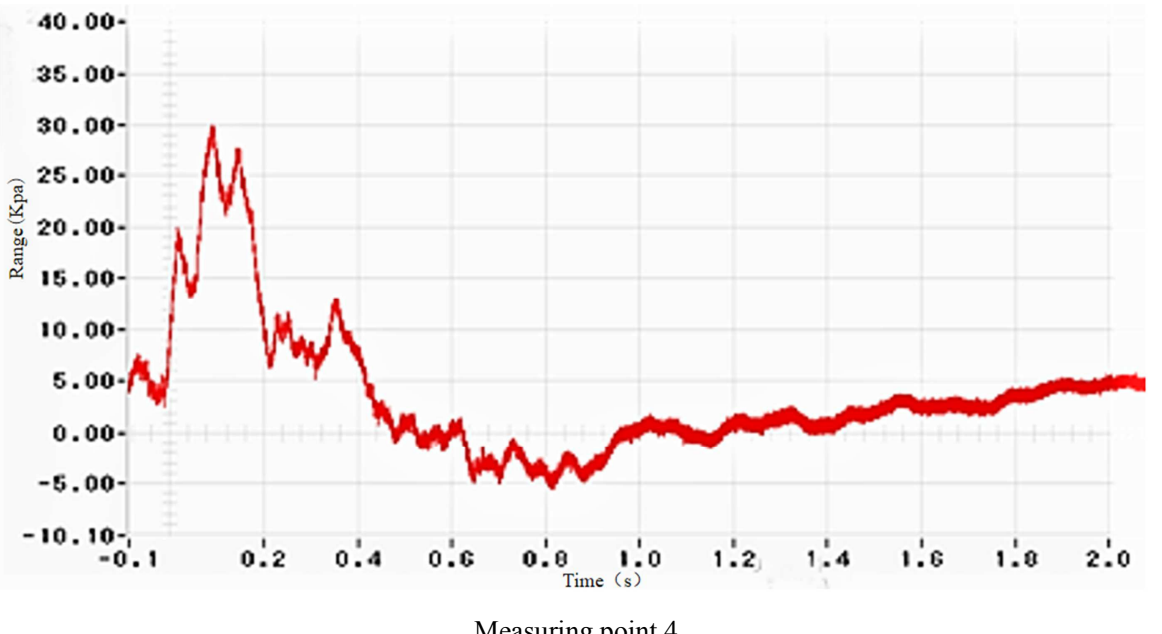

Figure 6. Measured typical shock wave waveform. 
Table 2. Summary of peak overpressure values of monitoring points.

\begin{tabular}{|c|c|c|c|c|c|c|c|c|c|c|c|}
\hline \multirow[b]{2}{*}{$\begin{array}{l}\text { Serial } \\
\text { number }\end{array}$} & \multirow[b]{2}{*}{$\begin{array}{l}\text { Monitoring } \\
\text { location }\end{array}$} & \multirow[b]{2}{*}{$\begin{array}{l}\text { Roadway } \\
\text { corner }\end{array}$} & \multicolumn{3}{|c|}{ Explosive volume (kg) } & \multirow{2}{*}{$\begin{array}{l}\text { Distance between the } \\
\text { first monitoring point } \\
\text { and the source of the } \\
\text { explosion (m) }\end{array}$} & \multirow{2}{*}{$\begin{array}{l}\text { First } \\
\text { measuring } \\
\text { point } \\
\text { (Kpa) }\end{array}$} & \multirow{2}{*}{$\begin{array}{l}\text { Second } \\
\text { measuring } \\
\text { point } \\
\text { (Kpa) }\end{array}$} & \multirow{2}{*}{$\begin{array}{l}\text { Third } \\
\text { measuring } \\
\text { point } \\
\text { (Kpa) } \\
\end{array}$} & \multirow{2}{*}{$\begin{array}{l}\text { Fourth } \\
\text { measuring } \\
\text { point } \\
\text { (Kpa) }\end{array}$} & \multirow{2}{*}{$\begin{array}{l}\text { Fifth } \\
\text { measuring } \\
\text { point } \\
\text { (Kpa) } \\
\end{array}$} \\
\hline & & & $\begin{array}{l}\text { Particle } \\
\text { explosive }\end{array}$ & $\begin{array}{l}\text { Rolled } \\
\text { explosive }\end{array}$ & total & & & & & & \\
\hline 1 & 560Working face & $90^{\circ}$ & 4475 & 120 & 4595 & 40 & 67.80 & 53.85 & 33.78 & 28.58 & 24.47 \\
\hline 2 & 500Working face & $90^{\circ}$ & 2075 & 792 & 2867 & 40 & 98.83 & 75.62 & 47.69 & 38.95 & 32.6 \\
\hline 3 & 450Working face & $30^{\circ}$ & 2900 & 1656 & 4556 & 90 & 35.81 & 27.12 & 20.93 & $*$ & 16.55 \\
\hline 4 & 470Working face & $30^{\circ}$ & 5650 & 2400 & 8050 & 120 & 51.97 & 45.68 & 35.65 & 28.85 & 22.83 \\
\hline 6 & 470Working face & $30^{\circ}$ & 1325 & 624 & 1949 & 120 & 46.53 & 39.74 & 30.08 & 27.07 & 24.02 \\
\hline
\end{tabular}

The protrusion and roughness of the roadway surface also have a certain influence on the propagation of shock waves. According to research by former Soviet scholar M. A. Sadowski and others. The roadway with the same cross-sectional shape and area is obtained, and the transformation formula of peak overpressure of friction loss is considered:

$$
\frac{\Delta \mathrm{P}}{\Delta \mathrm{P}^{\prime}}=e^{-\frac{\beta \mathrm{R}}{\mathrm{d}_{\mathrm{n}}}}
$$

The peak overpressure of the shock wave affected by the friction of the wall of the roadway is indicated by $\Delta \mathrm{P}, \mathrm{Kpa}$; The peak overpressure value of the shock wave that is not affected by the friction of the wall surface of the roadway is denoted by $\Delta \mathrm{P}^{\prime}$, Kpa; For the roadway wall roughness coefficient is denoted by $\beta$.

Therefore, the calculation formula (3) of the peak value of the blasting air shock wave propagating in the roadway with open ends can be converted into:

$$
\Delta \mathrm{P}=\left[\mathrm{b}_{1}\left(\frac{\mathrm{Q}}{\mathrm{SR}}\right)^{\frac{1}{3}}+\mathrm{b}_{2}\left(\frac{\mathrm{Q}}{\mathrm{SR}}\right)^{\frac{2}{3}}+\mathrm{b}_{3}\left(\frac{\mathrm{Q}}{\mathrm{SR}}\right)\right] e^{-\frac{\beta \mathrm{R}}{\mathrm{d}_{\mathrm{n}}}}
$$

The calculation formula of the peak value of the blasting air shock wave propagating in the tunnel opening at one end can be converted into:

$$
\Delta \mathrm{P}=\left[1.26 \mathrm{~b}_{1}\left(\frac{\mathrm{Q}}{\mathrm{SR}}\right)^{\frac{1}{3}}+1.59 \mathrm{~b}_{2}\left(\frac{\mathrm{Q}}{\mathrm{SR}}\right)^{\frac{2}{3}}+2 \mathrm{~b}_{3}\left(\frac{\mathrm{Q}}{\mathrm{SR}}\right)\right] e^{-\frac{\beta \mathrm{R}}{\mathrm{d}_{\mathrm{n}}}}
$$

The peak overpressure of the blasting shock wave is represented by $\Delta \mathrm{P}, \mathrm{Kpa}$; TNT explosive equivalent is represented by $\mathrm{Q}, \mathrm{kg}$; Roadway cross-sectional area is $\mathrm{S}, \mathrm{m}^{2}$; The propagation distance of the shock wave is represented by $\mathrm{R}, \mathrm{m}$; The equivalent diameter of the roadway is represented by $d_{n}, m$; Roadway wall roughness coefficient is represented by $\beta$.

Explosive mass Q in the above formula based on TNT explosives. Therefore, according to the principle of conservation of energy, the two explosives used in the on-site blasting operation are converted into the same amount of TNT explosive according to the explosive heat.

The explosives used in the blasting field operations are mainly No. 1 rock emulsion explosive (volume) and ANN-2 type sticky granular explosive (granule). The main

\begin{tabular}{|c|c|c|c|c|c|c|}
\hline Explosive name & $\operatorname{density}\left(\mathrm{g} / \mathrm{cm}^{3}\right)$ & $\begin{array}{l}\text { Explosion } \\
\text { speed }(\mathrm{m} / \mathbf{s})\end{array}$ & $\begin{array}{l}\text { explosive } \\
\text { violence }(\mathrm{mm})\end{array}$ & $\begin{array}{l}\text { performance } \\
\text { ability }(\mathrm{mL})\end{array}$ & $\begin{array}{l}\text { Gap distance } \\
\text { (cm) }\end{array}$ & $\begin{array}{l}\text { explosion heat } \\
(\mathrm{KJ} / \mathrm{kg})\end{array}$ \\
\hline 1\# rock emulsion explosive & $1.00 \sim 1.30$ & $\geq 4500$ & $\geq 16$ & $\geq 320$ & $\geq 4$ & * \\
\hline ANN-2 viscous granular explosives & 0.98 & $\geq 3200$ & $\geq 12$ & $\geq 298$ & $\geq 4$ & 2626 \\
\hline
\end{tabular}
performance parameters of the explosive are shown in table 3 .

Table 3. Main parameters of explosives.

The No. 1 rock emulsion explosive and the ANN-2 type cohesive granular explosive were replaced according to the TNT equivalent method, and the TNT equivalent conversion coefficient 1 of the No. 1 rock emulsion explosive proposed in the scholarly research results was changed. The ANN-2 type cohesive granular explosive has a TNT equivalent conversion coefficient of about 0.58 . Therefore, the amount of explosive

\begin{tabular}{|c|c|c|c|c|c|c|c|c|}
\hline \multirow{2}{*}{$\begin{array}{l}\text { Serial } \\
\text { number }\end{array}$} & \multicolumn{3}{|c|}{ Explosive quality (kg) } & \multirow{2}{*}{$\begin{array}{l}\text { granular } \\
\text { explosive TNT } \\
\text { conversion factor }\end{array}$} & \multirow{2}{*}{$\begin{array}{l}\text { Rolled explosive } \\
\text { TNT conversion } \\
\text { factor }\end{array}$} & \multicolumn{3}{|c|}{ Equivalent TNT explosive quality (kg) } \\
\hline & $\begin{array}{l}\text { granular } \\
\text { explosive }\end{array}$ & $\begin{array}{l}\text { Rolled } \\
\text { explosive }\end{array}$ & total & & & $\begin{array}{l}\text { granular } \\
\text { explosive }\end{array}$ & $\begin{array}{l}\text { Rolled } \\
\text { explosive }\end{array}$ & total \\
\hline 1 & 2625 & 1800 & 4425 & \multirow{7}{*}{0.58} & \multirow{7}{*}{1.00} & 1522.5 & 1800 & 3322.5 \\
\hline 2 & 2550 & 192 & 2742 & & & 1479 & 192 & 1671 \\
\hline 3 & 2500 & 1704 & 4204 & & & 1450 & 1704 & 3154 \\
\hline 4 & 3750 & 96 & 3846 & & & 2175 & 96 & 2271 \\
\hline 5 & 2450 & 96 & 2546 & & & 1421 & 96 & 1517 \\
\hline 7 & 1650 & 672 & 2322 & & & 957 & 672 & 1629 \\
\hline 8 & 3625 & 1584 & 5209 & & & 2102.5 & 1584 & 3686.5 \\
\hline
\end{tabular}
equivalent to TNT is obtained, as shown in table 4:

Table 4. Equivalent TNT dose conversion. 
The amount of TNT explosive equivalent $\mathrm{Q}_{0}$ on the site is converted into the explosive amount when it is exploded in the air. The conversion formula is as follows:

$$
\mathrm{Q}=\mathrm{K} \times \mathrm{Q}_{0}
$$

The equivalent amount of TNT explosive in the air is indicated by $\mathrm{Q}$; The equivalent amount of TNT explosive after conversion is represented by $\mathrm{Q}_{0}$; The correlation coefficient of the energy conversion of explosive energy into shock wave is represented by $\mathrm{K}$.

According to the actual situation of the site, the energy conversion coefficient corresponding to deep hole blasting in the stope is 0.3 . The energy conversion coefficient coefficient value is substituted into the formula for verification calculation, and the theoretical calculation value is basically corresponding to the field measured value. According to the drug conversion coefficient, combined with the field measured data of Table 1, the undetermined coefficients in the prediction formulas (5) and (9) of the blasting air shock wave peak overpressure are calculated:

Therefore, an optimal correction formula for accurately predicting the peak overpressure of the blasting air shock wave is obtained:

Prediction formula in the roadway with open ends:

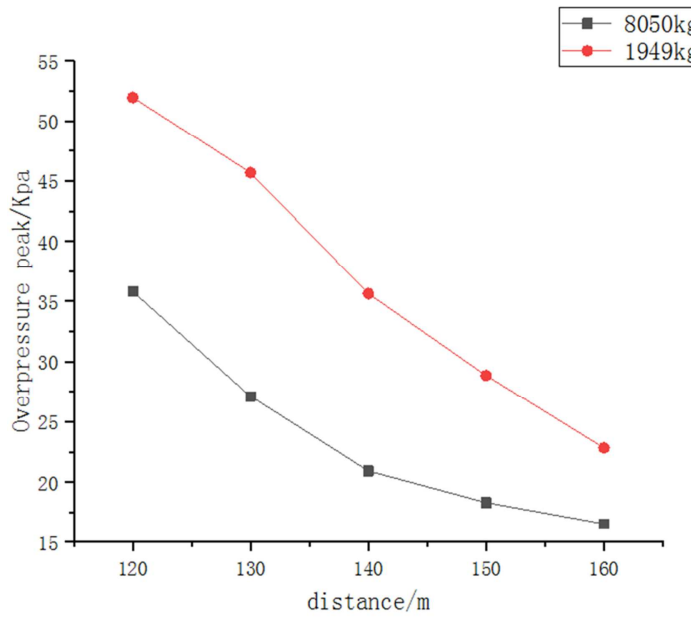

$30^{\circ}$ corner

$$
\Delta \mathrm{P}=\left[-0.165\left(\frac{\mathrm{Q}}{\mathrm{SR}}\right)^{\frac{1}{3}}+0.316\left(\frac{\mathrm{Q}}{\mathrm{SR}}\right)^{\frac{2}{3}}-0.037\left(\frac{\mathrm{Q}}{\mathrm{SR}}\right)\right] \times e^{-\frac{\beta \mathrm{R}}{\mathrm{d}_{\mathrm{n}}}}
$$

The prediction formula in the roadway with one end open is:

$$
\Delta \mathrm{P}=\left[-0.208\left(\frac{\mathrm{Q}}{\mathrm{SR}}\right)^{\frac{1}{3}}+0.502\left(\frac{\mathrm{Q}}{\mathrm{SR}}\right)^{\frac{2}{3}}-0.076\left(\frac{\mathrm{Q}}{\mathrm{SR}}\right)\right] \times e^{-\frac{\beta \mathrm{R}}{\mathrm{d}_{\mathrm{n}}}}
$$

The peak overpressure of the blasting air shock wave is represented by $\Delta \mathrm{P}, \mathrm{Mpa}$; The amount of TNT explosive is indicated by $\mathrm{Q}, \mathrm{kg}$; The cross-sectional area of the roadway is represented by $\mathrm{S}, \mathrm{m}^{2}$; The propagation distance of the shock wave is represented by $\mathrm{R}$; The equivalent diameter of the roadway is denoted by $d_{n}$; The roughness coefficient of the wall of the roadway is represented by $\beta$, Using 0.065 .

The explosion air shock wave propagates in a stable plane wave before it propagates to the turn of the roadway, and its propagation law follows the propagation law of the shock wave in the through-passway. Therefore, when analyzing the data of each measuring point in table 1, only the peak overpressure change before and after the corner of the roadway is considered, and the influence of the turning angle on the attenuation coefficient is studied.

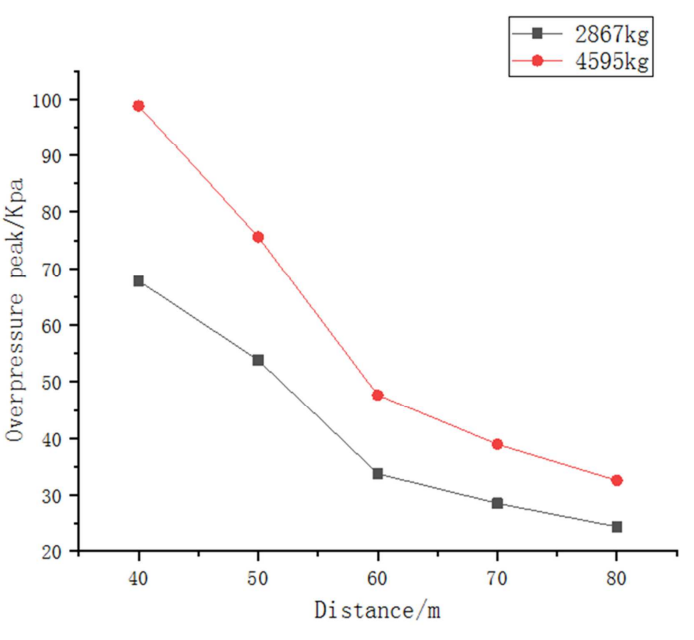

$90^{\circ}$ corner

Figure 7. Peak overpressure versus distance.

It can be seen from figure 7 that the peak overpressure value decreases with the increase of the distance as a whole, especially between the second point and the third point, and the downward trend between the third point and the fourth point begins to slow down. According to the arrangement of the site measurement points, the monitoring points before and after the corner are measured point 2 and measuring point 3, while at the measuring point 4 , the attenuation is relatively flat. Therefore, when calculating the attenuation coefficient corresponding to the rotation angle, the data of the measurement point 2 and the measurement point 3 are taken for research.
The calculation formula for the attenuation coefficient is:

$$
\lambda=\frac{\Delta \mathrm{P}_{1}}{\Delta \mathrm{P}_{2}}
$$

The attenuation coefficient of the peak overpressure of the shock wave is represented by $\lambda$, Indicates the amount of peak overpressure decay; The peak overpressure value before the air shock wave propagates to the turn is indicated by $\Delta \mathrm{P}_{1}$; The peak overpressure value after the shock wave returns to the plane wave after turning is denoted by $\Delta \mathrm{P}_{2}$. 
Therefore, according to the data of measuring point 2 and measuring point 3 in Table 1 , the peak overpressure attenuation coefficient corresponding to the turning angle is solved, that is, the attenuation coefficient corresponding to the peak overpressure after the air shock wave passes the $30^{\circ}$ rotation angle is $1.28 \sim 1.32$. The peak overpressure attenuation coefficient corresponding to the $60^{\circ}$ rotation angle is 1.33 , and the peak overpressure attenuation coefficient corresponding to the $90^{\circ}$ rotation angle is $1.58 \sim 1.59$.

\section{Simulation Study on the Propagation Law of Explosion Shock Wave in Downhole Turning Roadway}

The turning lane is also common in the mine shaft system. Unlike the tunnel in the through-passway, the explosion air shock wave will undergo a complex reflection phenomenon when passing through the lane corner, changing the original physical state of the shock wave flow field and forming an irregularity. Turbulent zone. Therefore, in view of this situation, this paper will use the turning lane as the research object to study the influence of the lane corner change on the air shock wave propagation.

\subsection{Constitutive Relations and Model Establishment}

The TNT explosive material model used in this simulation is the *MAT_HIGH_EXPLOSIVE_BURN material model and the *EOS_JWL equation. The expression of the *EOS_JWL equation of the TNT explosive is:

$$
\mathrm{P}=\mathrm{A}\left[1-\frac{\omega}{\mathrm{R}_{1} \mathrm{~V}}\right] \times \exp \left(-\mathrm{R}_{1} \mathrm{~V}\right)+\mathrm{B}\left[1-\frac{\omega}{\mathrm{R}_{1} \mathrm{~V}}\right] \times \exp \left(-\mathrm{R}_{2} \mathrm{~V}\right)+\frac{\omega \mathrm{E}_{0}}{\mathrm{~V}}
$$

$\mathrm{P}$ is the pressure; $\mathrm{V}$ is the relative volume, which is the ratio of the volume of the detonation product to the initial volume of the explosive. $E_{0}$ is the internal energy of the explosive unit volume; $\mathrm{A}, \mathrm{B}, \omega, \mathrm{R}_{1}$, and $\mathrm{R}_{2}$ are constants determined by the nature of the explosive.

Air in the model can be regarded as an ideal gas without viscosity, The simulated air material is defined by the *MAT_NULL material model and the state equation *EOS_LINEAR_POLYNOMAL. Therefore the air EOS equation expression is:

$$
\mathrm{P}=\mathrm{C}_{0}+\mathrm{C}_{1} \mu+\mathrm{C}_{2} \mu^{2}+\mathrm{C}_{3} \mu^{3}+\left(\mathrm{C}_{4}+\mathrm{C}_{5} \mu+\mathrm{C}_{6} \mu^{2}\right) \mathrm{E}_{0}
$$

$\mathrm{C}_{0}, \mathrm{C}_{1}, \mathrm{C}_{2}, \mathrm{C}_{3}, \mathrm{C}_{4}, \mathrm{C}_{5}, \mathrm{C}_{6}$ constants related to the nature of air itself, among them $\mathrm{C}_{0}=-1 \mathrm{e}-6, \mathrm{C}_{1}=\mathrm{C}_{2}=\mathrm{C}_{3}=\mathrm{C}_{6}=0$, $\mathrm{C}_{4}=\mathrm{C}_{5}=0.4, \rho, \mathrm{E}_{0}$ and $\gamma$ are the initial densities of the gas, respectively, Initial unit volume internal energy and adiabatic index. The parameters of the air material model are: $\rho=1.29 \times 10^{-3} \mathrm{~g} / \mathrm{cm}^{3}, \mathrm{E}_{0}=2.5 \times 10^{-6} \mathrm{MPa}, \gamma=1.4$.

The basic dimensions of the roadway model are not changed according to the size of the roadway before and after turning, that is, the length of the roadway is $100 \mathrm{~m}$, the section area is $14.24 \mathrm{~m}^{2}$, the corner of the turning point is about $60 \mathrm{~m}$, and the turning angle is $30^{\circ}, 60^{\circ}, 90^{\circ}, 120^{\circ}$. Model analysis was carried out in five cases of $150^{\circ}$. The explosive model is modeled by a cube. For the convenience of calculation, the amount of TNT explosive is $200 \mathrm{~kg}$. The roadway model also selects a roadway that is open at one end. Figure 8 below is a schematic diagram of the numerical simulation calculation model for the $30^{\circ}$ and $90^{\circ}$ turning lanes. The same is true for the turning lane model at other angles.
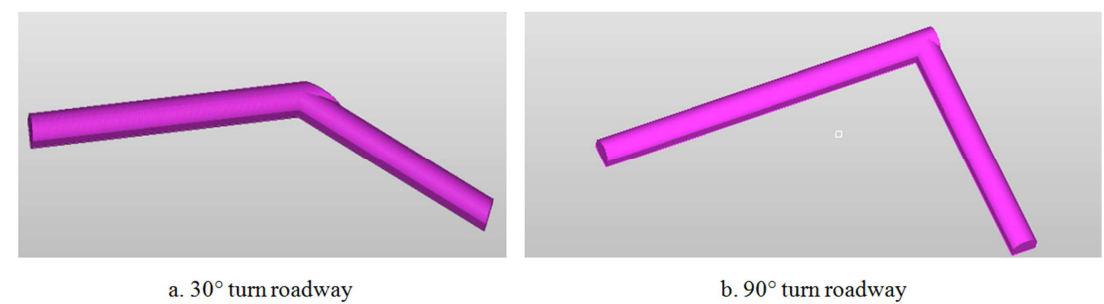

Figure $8.30^{\circ}, 90^{\circ}$ roadway model.

According to the turning angle of the roadway, taking into account the requirements of the article length, the simulation results of the $30^{\circ}$ and $90^{\circ}$ rotation angles are taken as an example. figure 8 shows the peak overpressure-time cloud image of the air shock wave propagating in the $30^{\circ}$ turning lane. figure 9 is $90^{\circ}$ Turn the roadway.

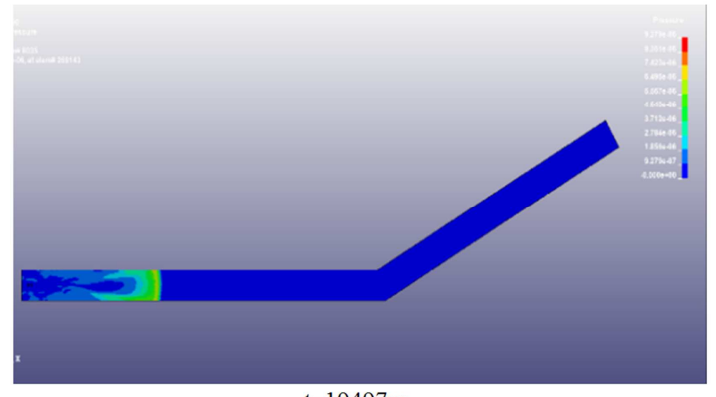

$\mathrm{t}=19497 \mathrm{us}$

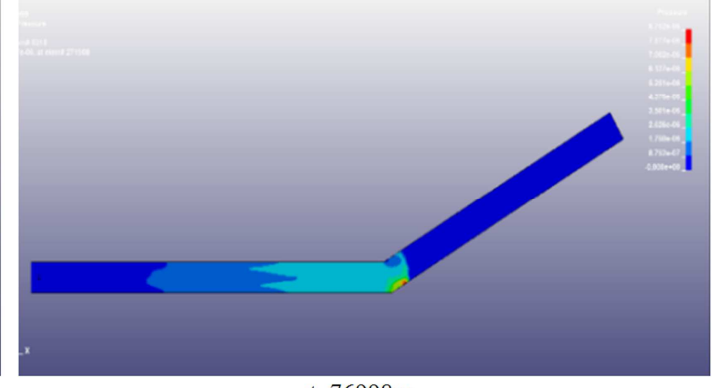

$t=76998$ us 


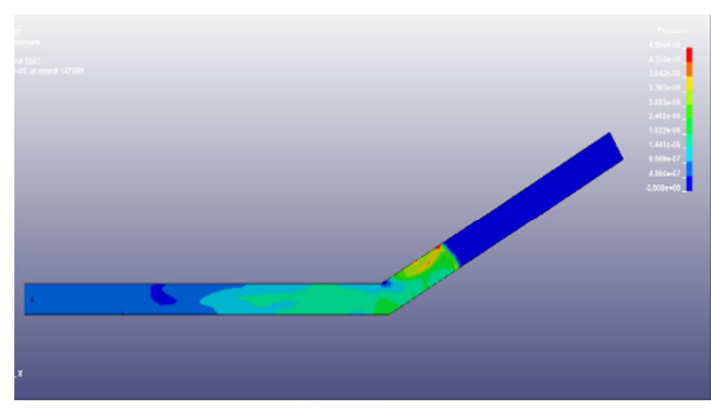

$\mathrm{T}=93000$ us

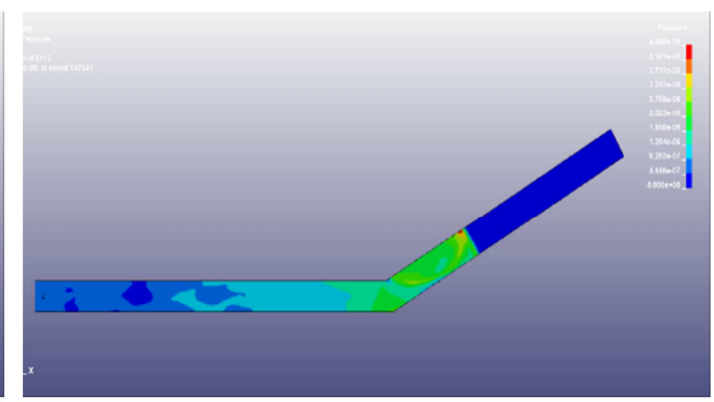

$\mathrm{T}=107487 \mathrm{us}$

Figure 9. Peak overpressure - time cloud map ( $30^{\circ}$ corner $)$.

Comparing figures 8 and 9 , it can be seen that the peak overpressure of the shock wave always follows the propagation law in the straight-through roadway from the formation of the air shock wave to the arrival of the shock wave to the turn of the roadway. When the shock wave propagates to the turning point, it can be clearly seen that the peak overpressure of the shock wave first decreases and then rises. At this time, the propagation law of the shock wave is completely different from the previous propagation state.

\subsection{Effect of Turning Angle on Peak Overpressure Attenuation}

After the explosion air shock wave passes through a certain angle of turning lane, it will be attenuated by the angle, which is usually expressed by the attenuation coefficient. From the conclusion of the peak overpressure-time cloud map, it can be seen that the air shock wave will generate a disordered zone after turning, and only after a certain propagation distance will it return to a stable plane wave. Therefore, it is necessary to determine the exact distance at which a plane wave is formed after turning, in order to better determine the attenuation coefficient.

\subsection{Study on the Influence of Turning Angle on Attenuation Coefficient}

According to the above research results, when studying the attenuation coefficient of the air shock wave after turning, the point of the central axis of the roadway section $20 \mathrm{~m}$ away from the turning point is taken as the reference point, and the reference point diagram is shown in figure 10 .

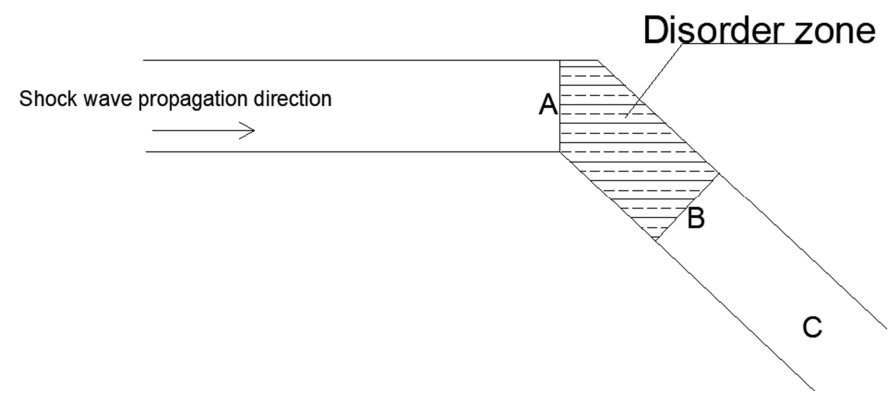

Figure 10. Schematic of the reference point position.

According to the above formula (13), the attenuation coefficient values in the roadway of each turning angle are calculated as follows:

Table 5. Attenuation coefficient values in the curved roadway.

\begin{tabular}{llll}
\hline \multirow{2}{*}{ Turning angle } & \multicolumn{2}{l}{ Overpressure peak $\Delta \mathbf{P}$ (Mpa) } & $\begin{array}{l}\text { Attenuation } \\
\text { coefficient }\end{array}$ \\
\cline { 2 - 3 } & $\Delta \mathbf{P}_{\mathbf{1}}$ & $\Delta \mathbf{P}_{\mathbf{2}}$ & 1.26 \\
\hline $30^{\circ}$ & 0.306 & 0.242 & 1.32 \\
$60^{\circ}$ & 0.301 & 0.220 & 1.46 \\
$90^{\circ}$ & 0.317 & 0.216 & 1.51 \\
$120^{\circ}$ & 0.305 & 0.202 & 1.67 \\
$150^{\circ}$ & 0.285 & 0.171 & \\
\hline
\end{tabular}

In order to facilitate the observation of the trend and correlation of the attenuation coefficient with the turning angle, the change graph of the attenuation coefficient corresponding to different turning angles is shown in figure 11 and the relationship between the attenuation coefficient and the turning angle is shown in the figure 12.

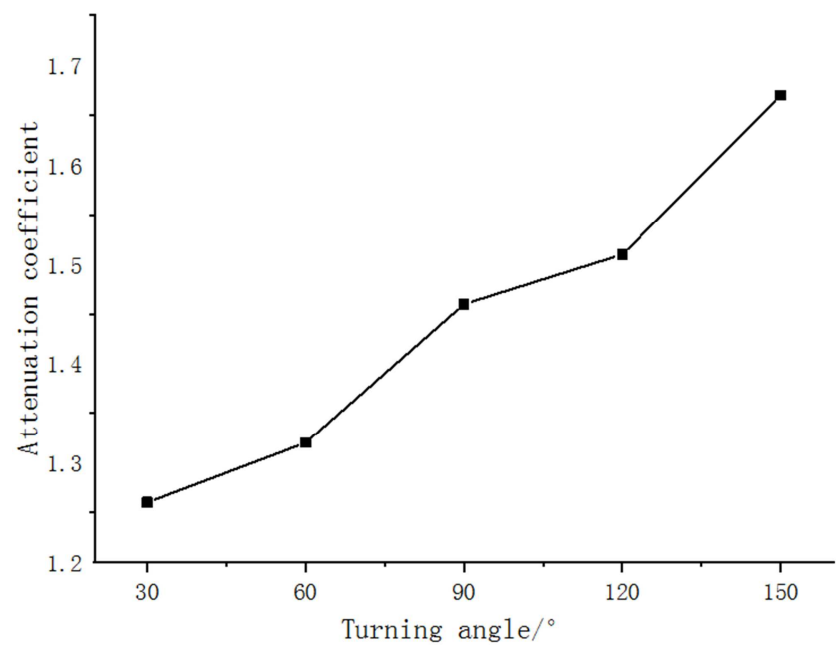

Figure 11. Attenuation coefficient as a function of angle.

It can be seen from the figure that the peak overpressure decay rate is larger between $60^{\circ}$ and $90^{\circ}, 120^{\circ}$ and $150^{\circ}$, and the decay rate is smaller between $30^{\circ}$ and $60^{\circ}, 90^{\circ}$ and $120^{\circ}$, and the attenuation coefficient of the explosion air shock wave The increase of the turning angle shows an increasing trend, that is, the larger the turning angle, the larger the peak overpressure value of the air shock wave is, and the more obvious the attenuation.

In order to better study the variation law of the peak overpressure attenuation coefficient in the turning lane with the turning angle, predict the specific value of the 
overpressure attenuation coefficient under different roadway angle changes, and fit the data in table 5:

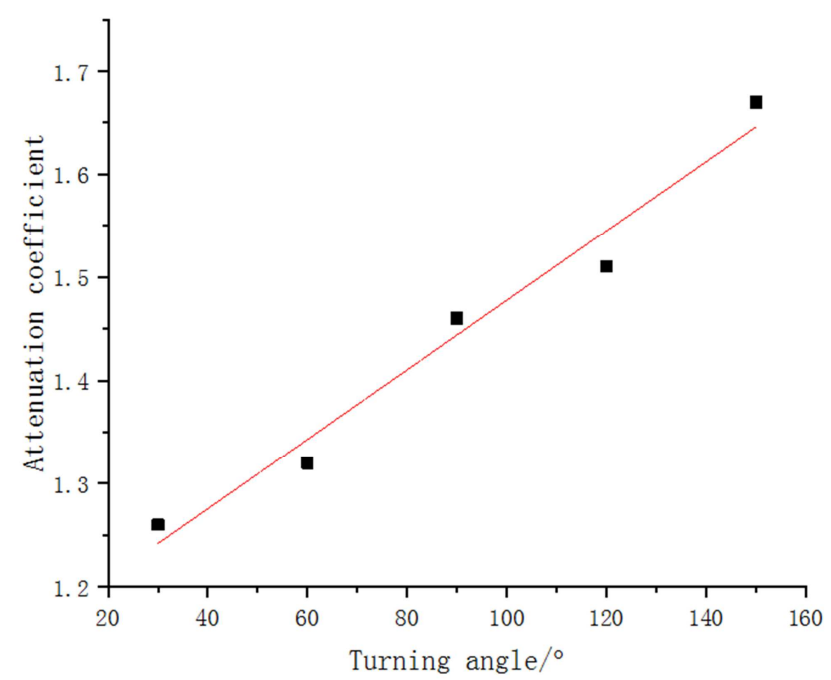

Figure 12. Linear relationship between attenuation coefficient and turning angle.

It can be seen from the fitting graph that when the turning angle of the roadway is between $0^{\circ}$ and $180^{\circ}$, the shock wave attenuation coefficient has a positive linear correlation with the turning angle of the roadway, which is in accordance with the relation: $y=1.141+0.00337 x$, and the correlation coefficient $\mathrm{R}$ is 0.972 . Explain that the fitting effect is good. The above-mentioned field measured data is brought into the relationship, and the results are basically consistent with the measured data, which has on-site guiding significance.

\subsection{Comparison of Simulated Calculation Results with Measured Values}

Compare the obtained attenuation coefficient with the value calculated in the second chapter, as shown in table 6.

Table 6. Measured attenuation coefficient values.

\begin{tabular}{llll}
\hline \multirow{2}{*}{ Turning angle } & \multicolumn{2}{l}{ Attenuation coefficient } & $\begin{array}{l}\text { Average } \\
\text { difference }\end{array}$ \\
\cline { 2 - 3 } & Measured value & Analog value & 0.04 \\
\hline $30^{\circ}$ & $1.28 \sim 1.32$ & 1.26 & 0.01 \\
$60^{\circ}$ & 1.33 & 1.32 & 0.075 \\
$90^{\circ}$ & $1.58 \sim 1.59$ & 1.46 & \\
\hline
\end{tabular}

Analysis of the above table data shows that the attenuation coefficient value obtained by the measured data is larger than the attenuation coefficient obtained by the simulation calculation. On the one hand, because the roadway itself is not flat enough, there is a large friction force, so that the peak value of the shock wave over the peak is reduced. Small, on the other hand, because the turning angle of the roadway is not standard, the angle corresponding to the field measured data is often approximated, which also makes the attenuation coefficient different. But in general, the actual attenuation coefficient value is very close to the analog calculation.

\section{Conclusion}

Based on the actual size of the mine shaft engineering, the ANSYS/LS-DYNA numerical simulation software is used to simulate the common roadway form in the turning tunnel. Combined with the field test, the explosion air shock wave is studied in the turning lane. Spreading the law, the following conclusions were drawn:

(1) In the curved roadway, the explosion air shock wave propagates to the turning point and follows the propagation law in the straight-through roadway.

(2) When the shock wave propagates to the turning point, a diffraction phenomenon and a strong reflection phenomenon occur, forming a disordered area. The range of the disordered area is within $20 \mathrm{~m}$ after the turning, and the shock wave gradually becomes a plane wave in a range other than $20 \mathrm{~m}$.

(3) The shock wave attenuation coefficient is matched with the turning angle of the roadway. When the turning angle of the roadway is $0^{\circ}$ to $180^{\circ}$, the attenuation coefficient has a linear correlation with the turning angle, which is important for the design of the roadway and the safety range. Reference value.

(4) The attenuation coefficient values corresponding to the five turning angles of $30^{\circ}, 60^{\circ}, 90^{\circ}, 120^{\circ}$, and $150^{\circ}$ are determined to be $1.26,1.32,1.46,1.51$, and 1.67, respectively. By fitting these points, we get in the turning lane. The law of the shock wave propagation, that is, the peak overpressure value of the air shock wave after passing through the turning lane is reduced before the turning, and the attenuation coefficient increases as the turning angle increases.

\section{Acknowledgements}

The authors greatly appreciate fund project: National Natural Science Foundation, for financially supporting part of this study, and the Yunnan Key Laboratory of Sino-German Blue Mining and Utilization of Special Underground Space research group at the Kunming University of Science and Technology for collaborations and providing facilities for research.

\section{References}

[1] Jia Zhiwei, Liu Yanwei, Jing Guoxun. Propagation characteristics of gas explosion shock wave in the case of pipeline turning [J]. Journal of China Coal Society, 2011, 36 (01): 97-100.

[2] Wu Yanjie, Gao Xuaneng. Numerical Simulation of Explosion Shock Wave and Correction of Overpressure Calculation Formula [J]. Journal of Huaqiao University (Natural Science), 2014, 35 (03): 321-326.

[3] Gong Wei, Wang Quan, Li Zhimin, et al. Study on the propagation law of explosion shock wave in cylindrical explosive container [J]. Blasting, 2017, 34 (04): 17-21+51. 
[4] Miao Zhaoyang, LI Xiu-di, YANG Sen, YAN Zhen-gang. Discussion on the similarity law of explosion shock wave in tunnel [J]. Blasting, 2016, 33 (01): 131-136.

[5] Li Xiudi, Zheng Yingren, Li Lizhen. The influence of charge position on the wave propagation law in the tunnel [J]. Journal of Chongqing University (Natural Science Edition), 2006, 29 (2): 95-98.

[6] Lu Hongqin, Liu Weiqing. Analysis of the influence degree of the cross-section shape of the tunnel on the propagation law of the explosion shock wave [J]. Journal of Nanjing University of Technology (Natural Science Edition), 2009, 31 (6): 41-44.

[7] Britan A, Igra O, Ben-Dor G, et al. Shock wave attenuation by grids and orifice plates [J]. Shock Waves, 2006, 16 (1): 1-15.

[8] Weiss E S, Cashdollar K L, Sapko M. Evaluation of explosion-resistant seals, stoppings, and overcast for ventilation control in underground coal mining [J]. Molecular \& Cellular Biology, 2002, 6 (1): 1.

[9] Kang Y., Wei M., Yan F., Su D., Zheng D., Wang X., et al. Crack Propagation Law Affected by Natural Fracture and Water Jet Slot under Blast Loading [J]. Combustion, Explosion, and Shock Waves, 2018, 54 (6): 747-756.
[10] Li Zhongxian, Shi Yanchao, Zhou Haozhang, Tian Li. Propagation law and overpressure load of blast wave in urban complex environment [J]. ENGINEERING MECHANICS, 2009, 26 (06): 178-183.

[11] Zhang Jiyun. Drivage roadway damage rule of gas explosion propagation dynamics and numerical study [D]. Hebei University of Engineering, 2014.

[12] Wei Hou, Zhiming Qu, Longjiang Pian. Numerical simulation on propagation and attenuation of shock waves in simplex turn roadway during gas explosion [J]. JOURNAL OF CHINA COAL SOCIETY. 2009, 34 (4): 509-513.

[13] Wang Yun-Yan, Qin Bin, Zhang Qi. Characteristic propagation features of the explosion air shock wave at the corner of tunnel [J]. JOURNAL OF SAFETY AND ENVIRONMENT. 2007, 7 (3): 105-106.

[14] Yang Shuzhao, DU Xuesheng. Study on pressure characteristics of gas explosion shock wave in driving tunnel $[\mathrm{J}]$. Journal of Hennan Institute of Engineering (Natural Science Edition). 2017, 29 (4): 35-38, 43.

[15] M. U. Yong. Numerical Simulation of Gas Explosive Shock Wave in Excavation Roadway [J]. COAL TECHNOLOGY. 2008, 27 (6): 92-94. 